\title{
Obesity as a Perceived Social Signal
}

\author{
Manasee Mankar ${ }^{1}$, Radhika S. Joshi ${ }^{1}$, Prajakta V. Belsare ${ }^{1}$, Maithili M. Jog $^{2}$, Milind G. Watve ${ }^{1,3 *}$
}

1 Department of Microbiology, Abasaheb Garware College, Pune, India, 2 Department of Biotechnology, Abasaheb Garware College, Pune, India, 3 Anujeeva Biosciences Pvt Ltd., Pune, India

\begin{abstract}
Fat accumulation has been classically considered as a means of energy storage. Obese people are theorized as metabolically 'thrifty', saving energy during times of food abundance. However, recent research has highlighted many neuro-behavioral and social aspects of obesity, with a suggestion that obesity, abdominal obesity in particular, may have evolved as a social signal. We tested here whether body proportions, and abdominal obesity in particular, are perceived as signals revealing personality traits. Faceless drawings of three male body forms namely lean, muscular and feminine, each with and without abdominal obesity were shown in a randomized order to a group of 222 respondents. A list of 30 different adjectives or short descriptions of personality traits was given to each respondent and they were asked to allocate the most appropriate figure to each of them independently. The traits included those directly related to physique, those related to nature, attitude and moral character and also those related to social status. For 29 out of the 30 adjectives people consistently attributed specific body forms. Based on common choices, the 30 traits could be clustered into distinct 'personalities' which were strongly associated with particular body forms. A centrally obese figure was perceived as "lethargic, greedy, political, money-minded, selfish and rich". The results show that body proportions are perceived to reflect personality traits and this raises the possibility that in addition to energy storage, social selection may have played some role in shaping the biology of obesity.
\end{abstract}

Citation: Mankar M, Joshi RS, Belsare PV, Jog MM, Watve MG (2008) Obesity as a Perceived Social Signal. PLoS ONE 3(9): e3187. doi:10.1371/journal.pone.0003187

Editor: Cuilin Zhang, National Institute of Child Health and Human Development/National Institutes of Health, United States of America

Received April 21, 2008; Accepted August 21, 2008; Published September 11, 2008

Copyright: (C) 2008 Mankar et al. This is an open-access article distributed under the terms of the Creative Commons Attribution License, which permits unrestricted use, distribution, and reproduction in any medium, provided the original author and source are credited.

Funding: The authors have no support or funding to report.

Competing Interests: The authors have declared that no competing interests exist.

*E-mail: milind_watve@yahoo.com

\section{Introduction}

Obesity and related disorders are a growing concern throughout the world. Although there are genetic predispositions to obesity, the number of genes involved is very large [1]. Furthermore the rapidly increasing frequency of overweight and obese individuals in many parts of the world cannot be due to increase in frequencies of any of the obesity related genes. Therefore more attention is focused on gene-environment-behavior interactions contributing to the obesity epidemic. Classically obesity is viewed as a means of energy storage. One of the popular classical concepts has been that of metabolic thriftiness [2,3]. The thrifty gene is said to confer the ability to store fat at times of food abundance and allow reutilization during food crunch. The thrifty phenotype [4] or thrifty epigenotype [5] concepts differ from thrifty gene concept in that they assume developmental plasticity and fetal programming rather than a set of genes to be responsible for thriftiness. Despite the differences between thrifty gene and thrifty phenotype hypotheses, the central axiom of thriftiness has remained largely unchallenged. These hypotheses have not been rigorously tested and many serious doubts about its validity have been raised [6-8]. The current perception is that obesity represents a positive energy balance, i.e. energy intake consistently exceeds energy expenditure and whether the current obesity epidemic is because of increased energy intake or reduced energy expenditure or both is seriously debated. Energy expenditure measurements using doubly labeled water have revealed that there is little difference in the total daily energy expenditure across societies, across lifestyles and over time $[9,10]$. This implies that energy intake might have increased. It is not clear however whether increased availability of food is the only factor responsible for increased food intake or other psycho-social factors are involved.

It is becoming increasingly clear, on the other hand, that adipose tissue has many more active roles than being an energy storage tissue alone. Adipose tissues are active endocrine organs directly or indirectly affecting metabolism, immunity, sex, reproduction as well as cognitive brain function [7,11-14]. Many social and behavioral angles of obesity are also coming to light recently. O'Rahilly and Farooqi [15], reviewing all known genetic mechanisms of obesity, concluded that obesity is a more of a neuro-behavioral than a metabolic phenomenon. Christakis and Fowler [16] demonstrated that obesity spreads through social networks. The mechanism behind the apparently socially contagious nature of obesity is not yet known. Christakis and Fowler [16] speculated on psychosocial means, such as changing norms about the acceptability of being overweight. An alternative possible reason can be speculated based on Briers et al [17] concept of a cross talk between food and money. Money is a very recent phenomenon in the evolutionary history of humans and therefore separate brain centres to handle money related emotions and information processing are unlikely to have evolved. The brain areas involved in handling food related emotions and information were presumably exapted to handle money. Therefore there could be a cross talk between the neural mechanisms of handling money and food. It's known that the region of the orbitofrontal cortex involved in processing food rewards is also involved in processing money rewards $[18,19]$. Briers et al $[17]$ showed that hunger affects money related decisions and the desire for money increases hunger. It is also possible that the desire to accumulate wealth results into a tendency to store fat [7]. Money and status related 
attitudes can be culturally transmitted through social networks and this may partly explain the network epidemiology of obesity.

There are further suggestions that obesity may act as a social signal $[7,20]$ revealing the past and present resourcefulness of a person. The role of central obesity is of particular interest. It is well known that central obesity is a better predictor of obesity related disorders and that visceral adipose tissue is metabolically more active than subcutaneous fat [21]. If the metabolic and behavioral role of adipose tissue and fat distribution as a social signal co-evolved, it makes much sense that metabolically active fat should be deposited abdominally. Subcutaneous fat is difficult to differentiate from muscle mass and therefore can be of little signal value. Abdominal fat, on the other hand, changes the body proportions substantially and therefore stands out quickly. For a person approaching from a distance, body proportions can be perceived much before facial expressions. Further the theory of honest signaling or the handicap principle states that only costly signals can be evolutionary-stable honest signals [22-24]. Fat has a high energy cost and therefore signaling by fat can evolve to be honest.

People are known to make personality judgments very quickly based on facial characters. The judgments are made instantaneously and thinking for a longer time appears to make little difference $[25,26]$. Furthermore subjects may not be able to state how they made these judgments suggesting that the judgments are not always made at a conscious level. Most of the studies are restricted to facial features and whether other parts of the body are used by people for instantaneous personality judgments has not been studied.

The hypothesis that fat has a social signal value can be tested at various levels. We test here only one aspect of it that is whether body proportions, as influenced by fat, are perceived to reflect any traits related to the physique, nature, attitude, moral character and status of a person; opening up a number of new questions such as whether the perception is right, whether the signals are honest and whether the associations are culture specific or universal.

\section{Methods}

Faceless drawings of three male body forms namely lean, muscular and slightly fat and feminine, each with and without abdominal obesity (designated as $L-, L+, M-, M+, F-$ and $F+$ respectively) [fig 1] were shown in a randomized order to a group of 222 respondents comprising 140 females and 82 males. All respondents were science students of an age group between 18 and 22 who voluntarily participated in the study with an informed consent. A list of 30 different adjectives or short descriptions of personality traits was given to each respondent and they were asked to allocate the most appropriate figure to each of them independently. The respondents were instructed to choose only one figure for each trait and not to leave any trait without a choice. Further they were asked to make a random choice if they did not find any 'reason' to assign any of the figures to a given trait and to note whether a given choice was with conscious reasoning (they were not expected to write reasons) or a random or 'just felt like' choice. The traits included those directly related to physique [strong, physically aggressive, lethargic, disease prone, swift, rough and tough] those related to nature [brave, friendly, talkative, intelligent, stupid, methodical], attitude [confident, conscious about looks, money minded, physical risk avoider, business risk avoider, depressed], moral character [greedy, selfish, political, kind, loving, honest] and also those related to social status [status conscious, rich, influential, dominating, successful, modern]. The study was restricted to male body forms for the fear that the social constraints and taboos on displaying naked female body forms in educational institutes may cause reluctance or bias the responses.

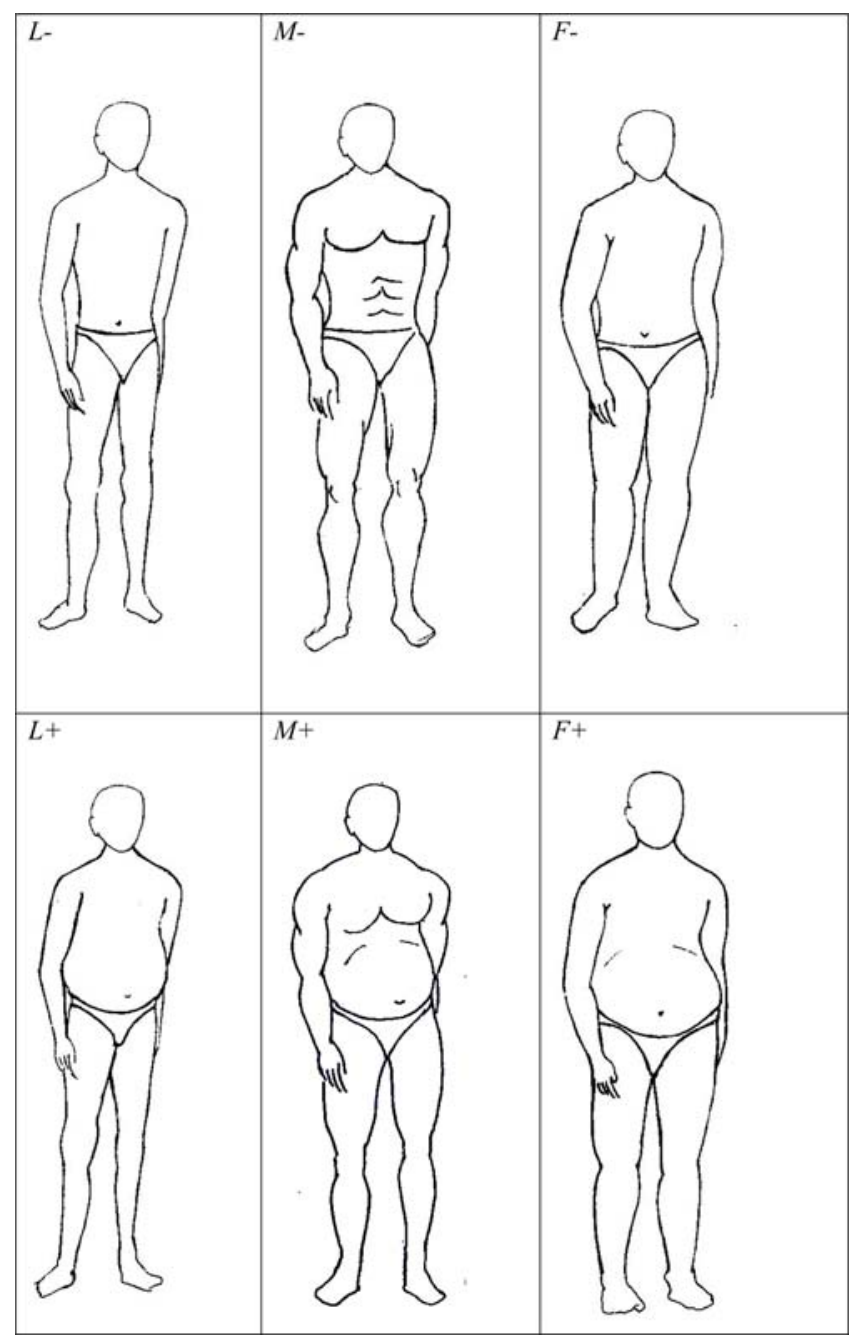

Figure 1. The six body forms used in the study: Three types of body forms were as shown in columns. 1. Lean ( $L$ - narrow shoulders, thin torso and extremities, knee and elbow joints thicker than thy and arm diameter). 2. Muscular ( $M$ - Broad shoulders, curved extremities, chest and abdominal muscles shown, thy and arm diameters greater than knee and elbow joints). 3. Slightly fat and feminine ( $F$ - rounded shoulders, cylindrical extremities). Each of the three body forms was represented with (designated by + ) and without $(-)$ abdominal obesity as shown in rows. The sequence of these figures was randomized during the test and the figures were labeled serially by alphabets.

doi:10.1371/journal.pone.0003187.g001

\section{Statistical methods}

For testing significance of choice of figure for each of the 30 traits separately, the null hypothesis that subjects choose any figure randomly for a given personality trait was tested using $\chi^{2}$ test with $\mathrm{df}=5$. For separately testing the effects of the three types of body forms and presence or absence of central obesity, frequencies were pooled in three and two appropriate categories respectively for $\chi^{2}$ tests. To test whether the effects of body form and abdominal obesity were independent or interacting, $\chi^{2}$ test for independence was performed using a three by two contingency table. Whether the gender of the respondent influenced the choice was also tested by a $\chi^{2}$ test for independence. Since a large number of tests were being carried out it was possible that some of the tests turned out to be significant by chance. As a possible solution the level of significance was reduced in inverse proportion to the number of 
tests being performed [27]. Since 5 different $\chi^{2}$ tests were being performed on 30 traits the working cut off should have been 0.05 / 150. We choose to be even more conservative by choosing $\alpha=0.0001$.

To test whether the subjects consistently associated some personality traits with each other, similarity scores were given to each pair of traits based on the frequency with which a given subject choose the same figure for both the traits. Statistical significance of pair-wise association was tested based on the following considerations. The null hypothesis that one of the six figures is assigned randomly to a given trait implies that the probability that two traits shared the same figure for a given respondent should be $1 / 6$. The chance similarities were assumed to be binomially distributed and therefore the mean n.p (where $\mathrm{p}$, the probability of a match $=1 / 6$ and $n=$ total number of responses for the given traits) was assumed to have an accompanying variance $n p q$. Since $n$ was large, the distribution could be considered approximately normal and similarity scores greater than $n p+2$ s.d. were considered significant positive associations and those less then $n p-2$ s.d. as significant negative associations. Based on a similarity matrix of all possible pairs of traits, cluster analysis was performed using unweighted pair group average method. Distinct clusters were defined based on the significance level calculated as above. For each of the clusters the proportions of each of the figures that contributed to the total similarity scores of the cluster were represented as a pie chart.

\section{Results}

Analyzing separately for each trait, the null hypothesis of random responses was rejected in all of the 30 traits. Since a large number of statistical test were involved a conservative level of significance was preferred. On using $\alpha=0.0001$, only one of the traits lost significance [Table 1]. All others remained highly

Table 1. Predominant positive and negative associations of personality traits with different body forms:

\begin{tabular}{|c|c|c|c|c|c|c|c|c|}
\hline Trait & $\begin{array}{l}\text { Pre- } \\
\text { dominant } \\
\text { positive } \\
\text { association }\end{array}$ & $\begin{array}{l}\text { Pre- } \\
\text { dominant } \\
\text { negative } \\
\text { association }\end{array}$ & $\begin{array}{l}\chi^{2} \text { for } \\
\text { random } \\
\text { responses }\end{array}$ & $\begin{array}{l}\chi^{2} \text { for } \\
\text { body form } \\
\text { alone }\end{array}$ & $\begin{array}{l}\chi^{2} \text { for } \\
\text { abdominal } \\
\text { obesity } \\
\text { alone }\end{array}$ & $\begin{array}{l}\chi^{2} \text { for in- } \\
\text { dependence }\end{array}$ & $\begin{array}{l}\chi^{2} \text { for sex } \\
\text { difference }\end{array}$ & $\begin{array}{l}\% \text { respondents } \\
\text { assigning with } \\
\text { reason }\end{array}$ \\
\hline Physically aggressive & $M-$ & $\mathrm{L}+, \mathrm{F}+, \mathrm{L}-$ & $536.22 *$ & 259.16 * & $104.07 *$ & 14.87 & 8.67 & 56.76 \\
\hline Strong & $M-$ & $\mathrm{L}-, \mathrm{L}+, \mathrm{F}+$ & $726.65 *$ & $319.16 *$ & $159.21 *$ & 6.73 & 8.48 & 65.77 \\
\hline Lethargic & $\mathrm{F}+$ & $M-, L-$ & 244 * & $89.21 *$ & $93.40 *$ & 10.12 & 24.53 & 45.95 \\
\hline Disease prone & $\mathrm{L}-, \mathrm{F}+, \mathrm{L}+$ & $\mathrm{F}-, \mathrm{M}-$ & $183.73 *$ & 121.97 * & 8.72 & $62.60 *$ & $27.23 *$ & 57.21 \\
\hline Swift & $\mathrm{L}-$ & $\mathrm{F}+, \mathrm{M}+$ & $61.94 *$ & 13 & $48.72 *$ & 2.04 & 9.35 & 32.43 \\
\hline Rough and tough & $M_{-}$ & $\mathrm{L}+, \mathrm{F}+, \mathrm{L}-$ & $560.54 *$ & 250.29 * & $127.13 *$ & 9.23 & 6.62 & 58.11 \\
\hline Confident & $M-, F-$ & $\mathrm{F}+, \mathrm{L}+$ & $208.81 *$ & $37.48 *$ & 133.26 * & 12.99 & $36.30 *$ & 46.40 \\
\hline Conscious about looks & $M-$ & $\mathrm{F}+, \mathrm{M}+, \mathrm{L}+$ & $215.73 *$ & $67.81 *$ & $73.80 *$ & $21.14 *$ & 5.02 & 52.25 \\
\hline Money minded & $\mathrm{F}+$ & $M-$ & 46.59 * & 15.11 & $23.35 *$ & 10.25 & 8.01 & 27.48 \\
\hline Physical risk avoider & $\mathrm{L}-, \mathrm{F}+$ & $\mathrm{M}+, \mathrm{F}-, \mathrm{L}+$ & $50.70 *$ & 2.78 & 4.05 & $43.69 *$ & 7.04 & 49.55 \\
\hline Business risk avoider & $\mathrm{F}-$ & $M-$ & 21.02 & 11.05 & 2.59 & 11.94 & 14.22 & 22.97 \\
\hline Depressed & L+ & $M-, F-$ & $161.89 *$ & $137.92 *$ & $18.45^{*}$ & $29.88 *$ & 9.27 & 38.74 \\
\hline Rich & $\mathrm{F}+$ & L- , L+ & $225.35 *$ & 131.38 * & 52.54 * & 1.33 & 17.34 & 42.34 \\
\hline Influential & $M-$ & $\mathrm{F}+, \mathrm{L}+$ & $98.65 *$ & 30.35 * & $50.61 *$ & 7.76 & 24.14 & 33.33 \\
\hline Dominating & $M-$ & $\mathrm{L}+, \mathrm{L}-$ & $147.40 *$ & 107.86 * & 22.07 * & 1.74 & 12.79 & 37.84 \\
\hline Successful & $\mathrm{F}-$ & $\mathrm{L}+, \mathrm{F}+$ & $171.62 *$ & $50.19 *$ & $83.31 *$ & 10.90 & 22.37 & 34.23 \\
\hline Status conscious & $M-$ & $\mathrm{L}+, \mathrm{L}-$ & $48.97 *$ & $34.89 *$ & 11.26 & 0.22 & 18.53 & 30.63 \\
\hline Modern & $M-$ & $\mathrm{L}+, \mathrm{F}+$ & $385.46 *$ & 125.11 * & $162.61 *$ & 1.52 & 10.31 & 45.05 \\
\hline Brave & $M-$ & $\mathrm{L}+, \mathrm{F}+$ & $294.65 *$ & 103.89 * & 142.72 * & 4.95 & 14.34 & 46.40 \\
\hline Friendly & $\mathrm{F}-$ & $\mathrm{M}-, \mathrm{F}+$ & $178.22 *$ & $44.35 *$ & $56.50 *$ & $56.05 *$ & 18.56 & 33.33 \\
\hline Talkative & $\mathrm{L}-, \mathrm{F}-$ & $M-, F+$ & $68.49 *$ & 14.38 & $22.07 *$ & $30.04 *$ & 19.34 & 23.42 \\
\hline Intelligent & $\mathrm{F}-$ & $\mathrm{F}+, \mathrm{M}+$ & $189.57 *$ & $39.35 *$ & $106.83 *$ & $19.62 *$ & 22.02 & 28.38 \\
\hline Stupid & $\mathrm{F}+, \mathrm{L}+$ & $M-, F-$ & 89.94 * & $18.92 *$ & $64.86 *$ & 4.51 & 3.41 & 20.27 \\
\hline Methodical & $\mathrm{F}-$ & $\mathrm{F}+$ & 91.51 * & 10.24 & $54.50 *$ & $21.28 *$ & 24.33 & 26.13 \\
\hline Loving & $\mathrm{F}-$ & $\mathrm{L}+, \mathrm{F}+, \mathrm{M}+$ & 170.38 * & $52.73 *$ & 64.86 * & 14.36 & $32.83 *$ & 22.07 \\
\hline Greedy & $\mathrm{F}+$ & $\mathrm{L}-, \mathrm{M}-$ & $295.89 *$ & 117.51 * & 98.67 * & 5.33 & 7.72 & 37.84 \\
\hline Selfish & $\mathrm{F}+$ & $M-, F-, L-$ & $67.03 *$ & 7.24 & $56.50 *$ & 5.54 & 15.76 & 19.37 \\
\hline Honest & $\mathrm{F}-$ & $\mathrm{F}+, \mathrm{M}+, \mathrm{M}-$ & 154.32 * & $38.19 *$ & $64.86 *$ & $23.61 *$ & $30.41 *$ & 27.03 \\
\hline Kind & $\mathrm{F}-$ & $M-$ & $123.45 *$ & $54.51 *$ & $28.83 *$ & 22.84 * & 16.53 & 25.23 \\
\hline Political & $\mathrm{F}+$ & $\mathrm{L}-, \mathrm{M}-$ & 95.84 * & 43.97 * & $45.04 *$ & 3.49 & 17.16 & 31.53 \\
\hline
\end{tabular}

Both body form and abdominal obesity appear to contribute to the judgment. For most of the traits chi square test for independence is non-significant indicating that the contributions of body form and abdominal obesity are independent of each other. Significance level $\alpha=0.0001$

doi:10.1371/journal.pone.0003187.t001 
significant. Body form and abdominal obesity both appeared to influence the choice in an independent manner in majority of the cases. There was significant interaction between the perception of body form and abdominal obesity in only 10 out of the 30 traits.

Physical characters were associated with the appropriate body forms as expected. The physical traits strong, rough and tough and physically aggressive were associated with the muscular non-obese $[M-]$ figure. Lethargic was associated with $F+$. Disease prone was significantly associated with $L-$ on the one hand and $F+$ on the other indicating that people negatively associate both the extremes with health. The trait swift was also strongly associated with $L-$. The traits that are not obviously physical were also strongly associated with certain body forms. Brave, conscious about looks, influential, dominating, status conscious, modern and confident were associated with $M-$; physical risk avoider, money minded, political, rich, stupid, selfish and greedy were associated most strongly with F+; friendly, intelligent, methodical, business risk avoider, successful, loving, kind, and honest were associated with $F-$; and $L-$ was the commonest choice for swift, physical risk avoider, talkative and the trait depressed was associated with $L+$ [table 1].

Gender of the respondent did not influence the choice of figures for 26 out of 30 traits. In the case of the trait honest, female respondents voted more for $F-$ and $F+$ whereas male respondents preferred $M-$ in greater proportion. In the case of three traits namely disease prone, loving and confident, female respondents favored the fat figure and male respondents the lean figure disproportionately more. There were no significant trends for other traits. We also considered the possibility that the BMI of the respondents may influence their choice. For example obese respondents may be more likely to assign 'good' traits to obese figures and lean respondents to lean figures. However we did not find any correlation between the respondent BMI and the frequency with which they assigned 'good' characters (brave, confident, friendly, strong, intelligent, kind, methodical, loving, swift, honest, modern, successful) to obese figures $(\mathrm{r}=0.032, \mathrm{p}=0.636)$.

The respondents were asked whether they could reason out their choices of figures for each trait. For physical traits the proportion of people choosing with reason was significantly higher (one factor ANOVA, $\mathrm{df}=4, \mathrm{~F}=6.76, \mathrm{p}=0.001$ ) as expected. For traits related to nature, attitude, moral character and social status, there was a high proportion of 'just felt like' responses. However the high level of concordance shows that these responses were highly nonrandom. This indicates that most of these choices could have been made at a subconscious level and although respondents largely converged on their choices, they were not able to give explicit reasons.

We further asked whether the personality traits had a consistent positive or negative association with each other. The similarity matrix based on common choice of figure by the same respondent revealed that a large number of pair-wise similarities were above the significance threshold for positive association. On the other hand, a large number of pairs showed significantly negative association as well [table 2]. Based on the similarity score the traits were clustered using unweighted pair group average method. At the significance cut off, 4 distinct clusters could be recognized [fig 2]. The first consisted of strong, rough and tough, physically aggressive, modern, brave, conscious about looks, dominating successful, confident, influential and status conscious and was dominated by $M-$. A second cluster included honest, intelligent, loving, friendly, kind, talkative and methodical and was dominated by $F-$. A third group of traits comprising depressed, disease prone and stupid was co-dominated by $L-, L+$ and $F+$. The forth distinct cluster consisted of traits including greedy, lethargic, rich, political, selfish and money minded was dominated by $F+$. The three figures with abdominal obesity namely $F+, M+$ and $L+$ constituted $87 \%$ of this cluster.

\section{Discussion}

The results indicate that the respondents significantly agreed on the choice of a particular body form for any given trait. The perceived associations were very strong and taking a highly conservative level of significance did not affect the results. Association of physical traits is not surprising since body proportions directly reflect physique. The physical characters work like positive controls for association and results for all of them are in the expected direction. Of specific interest are non-physical personality characters which show almost equally strong association with some or the other body form. Further traits related to social status, which could be considered independent of the physique by conventional wisdom were also strongly associated. This indicates that body proportions are perceived not only as indicators of health and physique as suggested by Pond [20] but also of nature, attitude, moral character and social status of an individual consistent with the Watve and Yajnik hypothesis [7]. The association of abdominal obesity with greedy, lethargic, rich, political, selfish and money minded is compatible with the soldierdiplomat dichotomy in metabolism conceptualized by Watve and Yajnik [7], according to whom abdominal obesity is a diplomat trait. Interestingly disease-proneness is associated with two extreme body forms namely $L-$ and $F+$. This is also consistent with the metabolic syndrome. Metabolic syndrome is known to be associated with obesity on the one hand and lipoatrophy on the other [28].

The proportion of random versus reasoned choices revealed that the respondents could not answer why and how they associated a particular figure with each of the characters. In an informal feedback after the test many expressed that they were not sure whether whatever they wrote made any sense. Some admitted that they had made completely 'random' choices. In spite of these typical reactions from respondents, the responses turned out to be highly non-random. The non-randomness of the responses is also revealed by the clustering of the traits which resulted into consistent personality clusters [fig 2].

The data at present are unable to indicate whether the associations have any biological basis or are shaped by cultural factors such as folklore, literature, cultural norms, role models or any other. A cross-cultural study may reveal whether some of the associations are culture independent universals. We found no effect of responder BMI and only marginal effect of sex. Our sample being small and homogeneous with respect to age, education and cultural background we could not detect the possible effects of these factors. Nevertheless the study demonstrates that people strongly associate body proportions with personality. This raises the possibility that social selection may have been an important force in the evolution of obesity related genes. Since obesity can affect personality judgments, it may influence mate choice- a process that has important direct effects on reproductive success. Other possible effects may include choice of people in possible co-operative alliances and other social interactions that would also ultimately influence reproductive success. It is common in human societies that different stereotyped personalities or role models are associated with different occupations. Even hunter gatherer societies are known to have occupational specializations such as shamans or magic-men. Therefore signaling one's personality by body proportions could have evolved as a natural and effective first level of communication. Similar to primate societies, the first interaction with any individual is likely to be tentative and suspicious. Here the ability to make quick judgments can be highly adaptive. The analysis, although only of a preliminary and exploratory nature, raises a 


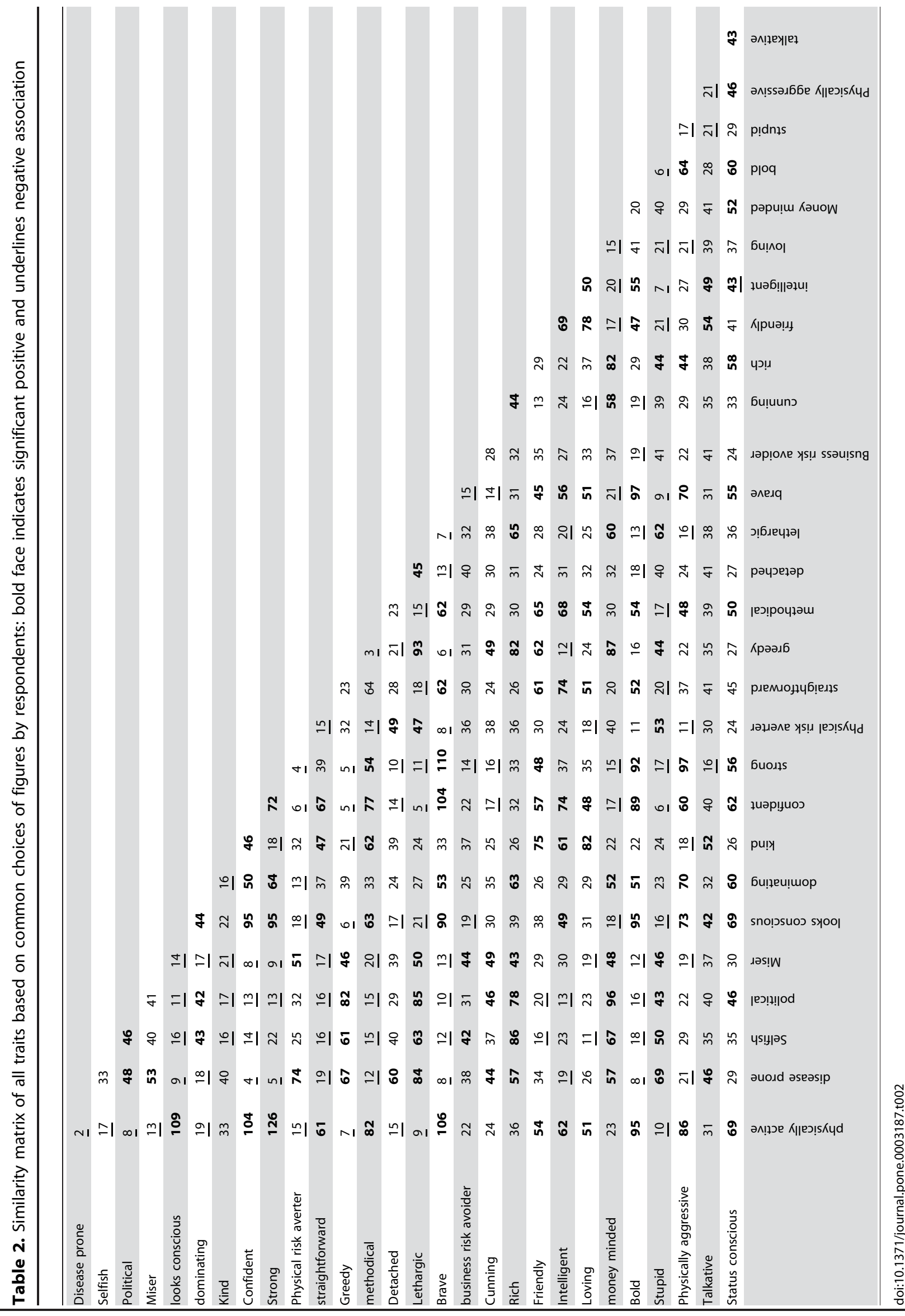




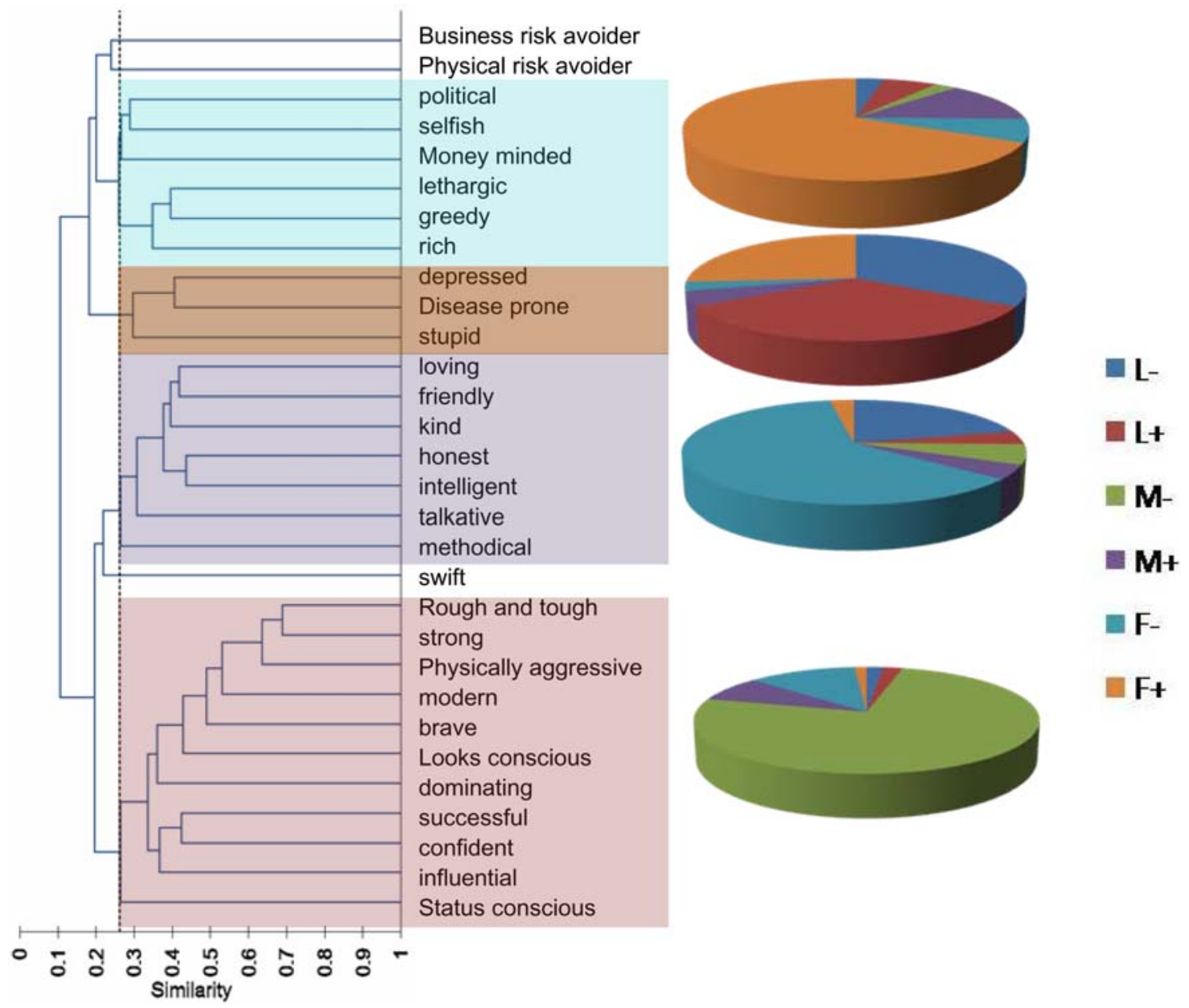

Figure 2. Clustering of personality traits based on the similarity matrix (table 2): Four distinct clusters emerged using the significance level of individual pair (alpha $=\mathbf{0 . 0 5}$ ) as the cut-off. The four clusters were dominated by different body forms as shown in the pie-charts.

doi:10.1371/journal.pone.0003187.g002

vast array of new questions that should facilitate deeper probe into the co-evolution of psychosocial, physical and metabolic functions.

Identifying the psychosocial aspects of obesity and related disorders has a definite relevance to their control and management. Over the past century the causes of obesity are being increasingly perceived as medical rather than behavioral. As a result the role of individual responsibility in preventing obesity is largely being downplayed [29]. A good understanding of the psychosocial factors can help attaining the right balance in the attitude towards obesity.

\section{References}

1. Reed DR, Lawler MP, Tordoff MG (2008) Reduced body weight is a common effect of gene knockout in mice. BMC genetics 9: 4 .

2. Neel JV (1962) Diabetes mellitus: a thrifty genotype rendered detrimental by progress? Am J Human Genet 14: 353-362.

3. Lazar MA (2005) How obesity causes diabetes: not a tall tale. Sci 307: 373-375.

4. Hales CN, Barker DJ, Clark PM, Cox LJ, Fall C, et al. (1991) Fetal and infant growth and impaired glucose tolerance at age 64. Br Med J 303: 1019-1022.

5. Stoger R (2008) The thrifty epigenotype: an acquired and heritable predisposition for obesity and diabetes? Bioessays 30: 156-66.

6. Speakman JR (2006) Thrifty genes for obesity and metabolic syndrome - time to call off the search? Diab Vasc Dis Res 3: 7-11.

7. Watve MG, Yajnik CS (2007) Evolutionary origins of insulin resistance: a behavioral switch hypothesis. BMC Evol Biol 7: 61

\section{Acknowledgments}

We thank Neelesh Dahanukar for help in statistical analysis, the research committee of Abasaheb Garware College for reviewing the study design for ethical clearence and all respondents of the test for their voluntary participation.

\section{Author Contributions}

Conceived and designed the experiments: MM RSJ MGW. Performed the experiments: MM RSJ PVB. Analyzed the data: PVB MMJ MGW. Wrote the paper: MMJ MGW.

8. Wells JCK (2007) The thrifty phenotype as an adaptive maternal effect. Biol Rev 82: $143-172$.

9. Black AE, Coward WA, Cole TJ, Prentice AM (1996) Human energy expenditure in affluent societies: an analysis of 574 doubly labeled water measurements. Eur J Clin Nutr. 50: 72-92.

10. Westerterp KR, Speakman JR (2008) Physical activity energy expenditure has not declined since the 1980s and matches energy expenditures of wild mammals. Int J Obesity. doi:10.1038/ijo.2008.74.

11. Marti A, Marcos A, Martinez JA (2001) Obesity and immune function relationships. Obes Rev 2: 131-140.

12. Esposito K, Giugliano D (2005) Obesity, the metabolic syndrome and sexual dysfunction. Int J Impotence Res 17: 391-398.

13. Norman RJ, Clark AM (1998) Obesity and reproductive disorders: a review. Reprod Fertility Dev 10: 55-63. 
14. Zhao WQ Alkon DL (2001) Role of insulin and insulin receptor in learning and memory. Mol Cell Endocrinol 177: 125-134.

15. O'Rahilly S, Farooqi IS (2006) Genetics of obesity. Phil Trans R Soc B 361: 1095-1105.

16. Christakis NA, Fowler JH (2007) The spread of obesity in a large social network over 32 years. New Eng J Med 357: 370-379.

17. Briers B, Pandelaere M, Dewitte S, Warlop L (2006) Hungry for money: the desire for caloric resources increases the desire for financial resources and vice versa? Psychol Sci 17: 939-943.

18. Breiter JS, Aharon I, Kahneman D, Dale A, Shizal P (2001) Functional imaging of neural responses to expectancy and experience of monetary gains and losses. Neuron 30: 619-639.

19. Elliot R, Newman JL, Longe OA, William Deakin JF (2003) Differential response patterns in the striatum and orbitofrontal cortex to financial reward in humans: a parametric functional magnetic resonance imaging study. J Neurosci 23: 303-307.

20. Pond CM (2001) Long term changes in adipose tissue in human disease. Proc Nutr Soc 60: 365-374
21. McKeigue PM, Shah B, Marmot MG (1991) Relation of central obesity and insulin resistance with high diabetes prevalence and cardiovascular risk in South Asians. Lancet 339: 382-386.

22. Zahavi A, Zahavi A (1997) The Handicap Principle: a missing piece of Darwin's puzzle. Oxford University Press.

23. Gintis H, Smith AE, Bowles S (2002) Costly signaling and cooperation. J theor Biol 213: 103-119.

24. Lachmann M, Szamado S, Bergstorm CT (2001) Cost and conflict in animal signals and human language. Proc Nat Acad Sci 98: 13189-13192.

25. Rule NO, Ambady N (2008) Brief exposures: male sexual orientation is accurately perceived at $50 \mathrm{~ms}$. J Expt Soc Psy doi:10.1016/j.jesp.2007.12.001.

26. Elfenbein HA, Ambady N (2002) On the universality and culture specificity of emotion recognition: a meta analysis. Psy Bull 128: 203-235.

27. Rice WR (1989) Analyzing tables of statistical tests. Evol 43: 223-225.

28. Kahn BB, Flier JS (2000) Obesity and insulin resistance. I Clin Invest 106: 473-481.

29. Chang VW, Christakis NA (2002) Medical modeling of obesity: a transition from action to experience in a $20^{\text {th }}$ century medical textbook. Sociology of health and illness 24: 151-177. 